repeat in the frataxin gene are not associated with type 2 diabetes or altered glucose induced $\beta$-cell finction in Danish caucasians. Diabetes 48: 914-917

6. 't Hart LM, Ruige JB, Dekker JM, Stehouwer CDA, Maasen JA, Heine RJ (1999) Altered $\beta$-cell characteristics in impaired glucose tolerant carriers of a GAA trinucleotide repeat polymorphism in the frataxin gene. Diabetes 48: 924-926
7. Huxtable SJ, Saker PJ, Haddad L et al. Analysis of parentoffspring trios provides evidence for linkage and association between the insulin gene and type 2 diabetes mediated exclusively through paternally-transmitted class III VNTR alleles. Diabetes (in press)

8. Pianese L, Cavalcanti F, de Michele G et al. (1997) The effect of parental gender on the GAA dynamic mutation in the FRDA gene. Am J Hum Genet 60: 460-463

\section{Effects of metformin on androgens and insulin concentrations in type A insulin resistance syndrome}

\section{Dear Sir,}

Insulin receptor gene mutations have been described in type A insulin resistance syndrome, characterized by hyperinsulinaemia, acanthosis nigricans and hyperandrogenism [1].

Non-obese women with polycystic ovary syndrome, a form of functional ovarian hyperandrogenism have an intrinsic form of insulin resistance that is unique to the disorder [2]. Treatment with insulin-sensitizing agents, such as metformin, has been shown to reduce insulin resistance, to statistically significantly decrease androgen concentrations and to initiate menstrual cyclicity in these patients [3]. These effects are consistent with the hypothesis that hyperinsulinaemia and insulin resistance have an aetiological role in hyperandrogenism through stimulation of ovarian and adrenal steroidogenesis.

We report the results of a 10-month treatment with metformin ( $850 \mathrm{mg}$ twice daily) in a lean (body mass index, 20 $\mathrm{Kg} / \mathrm{m}^{2}$ ), girl aged 13 years 6 months with severe hirsutism, acne, clitoral hypertrophy, acanthosis nigricans and primary amenorrhea. Basal hormonal assessment showed high total serum testosterone, 17-hydroxyprogesterone, androstenedione, immunoreactive insulin concentrations and decreased sex hormone-binding globulin concentrations. A tumoral origin of the hyperandrogenism was ruled out by appropriate imaging studies. Short-term leuprolide acetate stimulation (Procrin, Abbott, Madrid, Spain, $500 \mu \mathrm{g}$, s.c), elicited an increase in ovarian 17-hydroxyprogesterone concentrations (30.6 nmol/l) suggestive of functional ovarian hyperandrogenism. A standard oral glucose tolerance test produced insulin peaks of more than $3587 \mathrm{pmol} / \mathrm{l}$ at all time points, with normal glucose tolerance.
Molecular analysis of the insulin receptor gene showed a heterozygous novel missense mutation in exon 17 of the insulin receptor gene (Ala1028 $\rightarrow$ Val) abolishing autophosphorilation of the insulin receptor $\beta$-subunit.

Basal androgens and fasting insulin concentrations decreased significantly during treatment whereas sex hormonebinding globulin concentrations increased (Table 1). Breast development progressed and menarche occurred in the fifth month of therapy. No side-effects were documented.

Metformin is a biguanide hypoglycaemic agent that increases peripheral utilization of glucose, acting in the early steps of insulin signal transduction through potentiating phosphatidylinositol-3' kinase pathway of insulin receptors [4] and decreasing ovarian and adrenal cytochrome P450c17 activity [3]. Prolonged treatment with metformin has been proved to be safe in Type II (non-insulin-dependent) diabetes mellitus and in a pregnant hyperandrogenic woman [5]. Metformin, troglitazone (a thiazolidinedione derivative) and the D-chiroinositol-containing phosphoglycan mediator of the action of insulin, reduce hyperinsulinism and hyperandrogenism in women with functional ovarian hyperandrogenism. The new agent L-783,281, recently identified as a non-peptidyl fungal metabolite, seems to act by stimulating tyrosine kinase activity of insulin receptors [7]. Although this drug might have beneficial effects in insulin resistance states due to insulin receptor mutations in the $\alpha$-subunit, it might be ineffective in tyrosin kinase domain mutations of the insulin receptor in which this activity is abolished.

Our results show the usefulness and safety of metformin therapy in an adolescent with type A insulin resistance syndrome associated with severe hyperandrogenism.

Yours sincerely, S. Rique, L. Ibáñez, M. V. Marcos, A. Carrascosa, N. Potau

Table 1. Clinical data, androgen and sex hormone-binding globulin concentrations and fasting glucose and insulin concentrations before and after 5 and 10 months of metformin treatment ( $850 \mathrm{mg}$ twice daily)

\begin{tabular}{llllllllll}
\hline & $\begin{array}{l}\text { Tanner } \\
\text { breast stage }\end{array}$ & $\begin{array}{l}\text { hirsutism } \\
\text { score }\end{array}$ & $\begin{array}{l}\text { TT } \\
\text { nmol/l }\end{array}$ & $\begin{array}{l}\text { SHBG } \\
\text { nmol/l }\end{array}$ & FAI & $\begin{array}{l}\text { 17-OHP } \\
\text { mmol/l }\end{array}$ & $\begin{array}{l}\Delta^{4} \text {-A } \\
\text { nmol/1 }\end{array}$ & $\begin{array}{l}\text { glucose } \\
\text { mmol/l }\end{array}$ & $\begin{array}{l}\text { insulin } \\
\text { pmol/1 }\end{array}$ \\
\hline Baseline & II & 20 & 8.3 & 31.2 & 13.5 & 10.5 & 12.0 & 4.9 & 1127.9 \\
5 months & III & 17 & 2.1 & 48.6 & 6.4 & 1.9 & 10.9 & 4.2 & 581.8 \\
10 months & V & 10 & 1.7 & 48.6 & 4.3 & 1.9 & 10.8 & 4.3
\end{tabular}

${ }^{\mathrm{a}}$ Ferriman and Gallwey score (normal $\leq 8$ ); TT, total testosterone; SHBG, sex hormone-binding globulin; FAI, free androgen index (equivalent to free testosterone; normal $\leq 5$ ); 17-OHP, 17-hydroxyprogesterone; $\Delta^{4}$-A, androstenedione.
Normal values for age-matched control girls (mean $\pm \mathrm{SD}$; $n=40)$ : TT, $0.7 \pm 0.3 \mathrm{nmol} / \mathrm{l} ; \mathrm{SHBG}, 59.0 \pm 6.9 \mathrm{nmol} / \mathrm{l}$; $17-$ OHP, $\quad 1.8 \pm 0.01 \mathrm{nmol} / \mathrm{l} ; \quad \Delta^{4}-\mathrm{A}, \quad 4.4 \pm 1.7 \mathrm{nmol} / \mathrm{l} ; \quad$ insulin, 35.9-107.6 pmol/1

Corresponding author: N. Potau MD, Hormonal Laboratory, Hospital Materno-Infantil Vall d'Hebron, Passeig Vall d'Hebron 119-129, E-08035 Barcelona, Spain 


\section{References}

1. Tritos NA, Mantzoros CS (1998) Syndromes of severe insulin resistance. J Clin Endocrinol Metab 83: 3025-3030

2. Dunaif A (1997) Insulin resistance and the polycystic ovary syndrome: mechanism and implications for pathogenesis. Endocrinol Rev 18: 774-800

3. Nestler JE, Jakubowick DJ (1996) Decreases in ovarian cytochrome P450c17 activity and serum free testosterone after reduction of insulin secretion in polycystic ovary syndrome. N Engl J Med 335: 617-634

4. Grigorescu F, Poucheret P, Bouix O et al. (1998) Metformin potentiates phosphatidylinositol-3' kinase by IRS-2 recruitment in rat hepatic tissue. Diabetologia 41 [Suppl 1] 189 A (Abstract)
5. Sarles NJ, Weil SJ, Nelson LM (1999) Administration of metformin to a diabetic woman with extreme hyperandrogenemia of nontumoral origin: management of infertility and prevention of inadvertent masculinization of a female fetus. J Clin Endocrinol Metab 84: 1510-1512

6. Nestler JE, Jakubowicz DJ, Reamer P, Gunn RD, Allan GA (1999) Ovulatory and metabolic effects of D-chiro-inositol in the polycystic ovary syndrome. N Engl J Med 340: 1314-1320

7. Zhang B, Salituro G, Szalkowski D et al. (1999) Discovery of a small molecule insulin mimetic with antidiabetic activity in mice. Science 284: 974-977

\section{Measurement of T-cell autoreactivity in autoimmune diabetes}

Dear Sir,

We sincerely applaud the organisers of the IDS-sponsored, first international T-cell workshop, who undertook and completed a very difficult task [1]. The purpose of this first T-cell workshop and its less ambitious successors, is to develop robust techniques for the measurement of T-cell autoimmunity in Type I (insulin-dependent) diabetes mellitus-prone subjects [2]. This would provide new mechanistic insight, improve staging of prediabetes and, eventually, allow us to measure the effectiveness of intervention therapies well before onset of overt disease.

In this search for better procedure and technology, we all are still beginners. It took well over a decade to refine diabetes autoimmune serology to its present, quite reliable status. Autoantibodies could, however, be rather late markers of progressive autoimmunity, and the efforts to measure autoreactive Tcells in a disease principally mediated by $\mathrm{T}$-cells are rational and important.

In the first workshop, 29 laboratories tested 24 diabetes-relevant antigens. It was probable that not all these antigens would be recognised equally by the diverse study cohorts of patients, relatives and unrelated control subjects, hence the variety of test antigens. One initial goal was to find, in a blinded protocol, culture conditions that allowed a distinction between control subjects and patients (and perhaps relatives), with a reasonable subset of antigens.

The data eventually generated were analysed with care. The results of this analysis were disappointing. Data analysis is, however, always influenced by certain basic assumptions and is often open to interpretations. When we received the workshop data, we concluded that, rather than none $[1,2]$, there were five laboratories (numbers 3, 8, 10, 15, 23) which could detect disease-associated T-cell responses to four to seven of the test antigens.

Some of these responses would have been excluded by the workshop data analysis team, due to their choice of a hard cut-off for positive responses. In our hands, the mean stimulation index of ovalbumin stimulated cells plus four standard deviations produced a cut-off for positive responses that distinguished positive patient from negative control subject respons-

Corresponding author: H.-M. Dosch, MD, Department of Paediatrics, IIIR Program, The Hospital For Sick Children, 555 University Ave., Toronto, Ont., Canada, M5G 1X8 es to over ten 'diabetes antigens' in blinded studies of several hundred patients, relatives and healthy controls [3].

The Toronto-Pittsburgh collaborative team supplied two sets of T-cell response data to the workshop: those with and those without a small interleukin 2 (IL2) supplement. By the time of the T-cell workshop, we had garnered evidence, that abnormal T-cell anergy was common in diabetic patients and that $\mathrm{T}$-cell responses were small but could be rescued by exogenous IL2 in our serum-free cultures [4]. This has since been substantiated $[3,5]$.

Data from IL2-supplemented cultures were not evaluated by the workshop committee, because of confidentiality rules: IL2 supplements would have identified our laboratory. We acknowledge this rationale but as we all are still searching for basic assay alternatives, we here provide the data set from IL2-supplemented cultures, blindly submitted to the workshop years ago.

Figure 1 shows the proportions of positive responses elicited by the test antigens. Incorporation of $\mathrm{H}^{3}$-thymidine in ovalbumin-stimulated and non-stimulated cultures was not statistically different ( $p$ values $>0.6)$. In this small data set IA2, ICA69 and some GAD65 preparations were most frequently targeted by diabetic autoimmunity.

Children with recent onset Type I diabetes $(n=10)$ generated 47 positive responses to the test antigens (not counting tetanus toxoid, TT), 16 were observed in the first-degree relative's (FDR) group $(n=3)$ and 3 were generated by the seven healthy control subjects (Fig. 1 insert). The distinction of patients and healthy control subjects was significant $(p<0.0001$, relative risk 10.97 [95\% CI 3.5-34.6]). Of the three first-degree relatives tested, two had responses to many of the test antigens, one did not, the former two are prospectively followed as part of a high risk relative's cohort [6]. Several workshop laboratories used first-degree relatives in their control group. Because relatives often show signs of diabetic autoimmunity, this could have contributed to a lack of distinction between patients and control subjects.

Serum-free culture systems with small IL2 supplements may be promising techniques for the detection of disease-associated T-cell autoreactivities in autoimmune diabetes. In our hands, T-cell autoreactivity without IL2 supplements is too variable for analysis. Other laboratories which use serum supplemented culture systems seem, however, to bypass some or much of the IL2 requirement, perhaps through cytokine release from bystander T-cells (e.g. [7, 8]).

Sincerely Yours, H.-M. Dosch, D.J. Becker 